\title{
CORRESPONDENCE.
}

\section{ON MR. BAILEY'S ESTIMATE OF THE LIABILITIES OF CERTAIN}

\section{LIFE ASSURANCE COMPANIES.}

\section{To the Editor of the Assurance Magazine.}

Srr,-It is not usual to discuss, in the Assurance Magazine, the accounts of individual Companies, or the merits of the various methods of division of profits employed by them; and it wonld be matter of regret if such discussions were generally allowed to appear in your pages. But when there is reason to think that an injustice has been done to a particular Company by one of your correspondents, I doubt not that you will allow your usual salutary rule to be relaxed so far as may be necessary to correct that injustice.

I refer to Mr. Bailey's table, which appeared in the Assurance Magazine for July, 1863 (vol. xi., pp. 111, 112), and purports to show the "estimated liability" of various Offices. I may say for myself that I entertain a very low opinion of the value of such general comparisons as are afforded by the table in question. Mr. Bailey has pointed out one disturbing element in the numerous recent amalgamations which have occurred; bat this is far from being the only eanse which interferes with the fairness of the comparison, or the most important one. It is obvions that if, of two Ofices of the same standing, one has done a new business generally increasing in amount from year to year, while the new business of the other has been rather falling off, then the liability of the latter must be greater in proportion to the sum assured than is the case with the former. There is at least one marked instance of the effect of this cause apparent in Mr. Bailey's table (p. 112).

In order that such tables may have any valne at all, it is of conrse essential that the figures given in them should be accurate, and that they should be deduced from the published statements of the Offices by a process which admits of no dispute. Now, there are two Offices, which I will call (A) and (B), included in Mr. Bailey's list, which appear to make a much smaller reserve for their liabilities than most other Offices of similar standing; but this is not really the case, as I will presently show. In fact, it appears to me that the acconnts of these two Offices have been treated erroneously, and that the correct sums to be tabulated as the ralues of the estimated liability are much larger than those given in the table. In the Office $A$, which had been established for 54 years on 30 th June, 1862, the sum assured at that date was $\mathfrak{f} 6,526,853$; and the

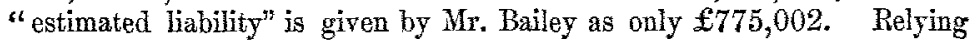
on the accuracy of these figures, I have on various occasions expressed myself, in the course of conversation, to the effect that "the Office in question makes a very small reserve for its liabilities;" and it cannot be dispnted that this is the obvious conclusion to be drawn from the table. Having made the above statement to a friend who is insured in it, he challenged me to prove my assertion, and placed in my hands the printed accounts of the Association for a series of years; and I have now to acknowledge that an examination of these accounts has led me to a conclusion very different from Mr. Bailey's.

\footnotetext{
* More accurately $55 \frac{3}{2},-E D, A, 14$.
} 


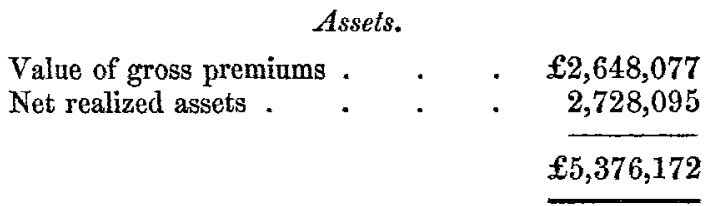

It thus appears that Mr. Bailey has deducted from the assurance fund of the Association the value of the future reduction of premium; and I presume he would justify this course by argning, that although the reduction of preminm is variable and uncertain, being declared from year to year, yet the hope is held out by the Association that the present reduction may be permanently maintained. Assuming for the present that the reduction is to be considered permanent in the case of (A) and (B), then $I$ have to observe that the accounts of these Offices are treated in Mr. Bailey's table in a very different manner to those of the other Offices mentioned. In all the other instances the values of the bonuses declared, and of any permanent reductions of premium, are included in the "estimated liability"; and in one instance-the Equitable-it is pointed ont that the magnitude of the bonuses bas a great influence in raising the amonnt of the estimated liability. Consistency, therefore, certainly requires that if the reduction of preminm in (A) is considered as a permanent thing, its value ought to be included in the estimated liability, which is therefore raised to $f 2,728,095$; amounting, as already stated, to $41 \cdot 8$ per cent. on the sum assured.

Bat there can be no doubt that the above is not the correct way of regarding the reduetions of premium declared by the two Offices in question. Those reductions are fixed every year in conformity with the results of the valuation then made; and are subject to increase or diminution, from year to year, according as the experience of the Office in the past year has been favourable, or the contrary. It is therefore more correct, as well as more convenient for the purpose of comparison with other Offices, to say that an annual cash bonus is deelared, equal to the value of the abatement of premium allowed for the ensuing year. Thus then the direetors of $(A)$, in submitting to the members the balance sheet of which a summary has been given above, are to be regarded as saying- "We declare an abatement of premium for the year ending 30th June, 1863, of $83 \frac{1}{2}$ per cent. for the members of the 1 st series, and $73 \frac{1}{2}$ per cent. for such members of the second series as are entitled to an abatement; and these abatements are calculated on such a seale that they may reasonably be expected to be maintained from year to year so long as the experience of the Society continues similar to its present experience." An examination of the balance sheet leads to the concinsion that the abatements may be maintained on the present seale, so long as the expenses of management are defrayed ont of the excess of interest realized over the rate at which the valuations are made (which is eurrently reported to be 4 per cent.); and the incidental profits arising from surrenders, from the premiums upon non-members' policies, \&c.;-provided the mortality experienced does not exceed that calculated upon in the table of mortality used in the valuations.

In order to reconstruct the balance sheet in a proper form for comparison with the accounts of other Societies, it is necessary to ascertain approximately the amont of the abatement of premium for the year 
ending 30th June, 1863. It is stated in the printed account of the Association from which the above figures are taken, that the gross annual premiums on all existing policies amount to $£ 228,800$; that the premiums on non-members' policies are $£ 5,612$, and the premiums on the policies of

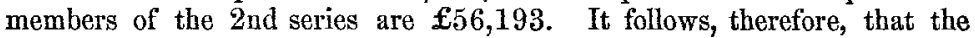

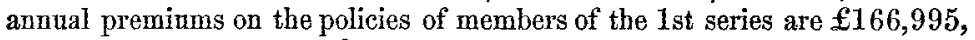

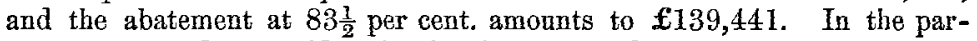
ticular year under consideration it will be found that all the members of the 1 st series were entitled to abatement, having paid seven premiums, but none of the second series were yet entitled to an abatement. Now, arranging the balance sheet in the form usually adopted when the value of the gross premiums is stated, it will be as follows:-

\section{Liabilities.}

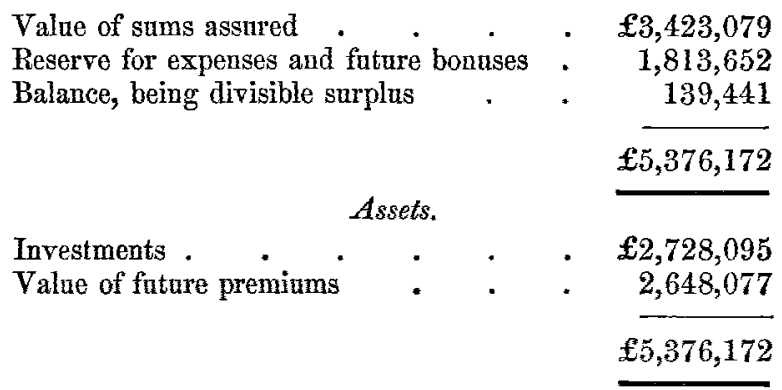

It will be noticed, however, that in strict accuracy the surplus should be the value of the year's abatement of preminm, instead of the amonnt of that abatement. It thus appears that when the accounts of this Office are treated in the same way as those of the other Societies considered by Mr. Bailey, it is found that, on 30 th Jane, 1862, no less than $68 \frac{\mathrm{I}}{2}$ per cent. of the value of the future gross premiums was reserved for expenses and future bonuses, and the "estimated liability" was $(\mathfrak{f 2}, 728,095-$

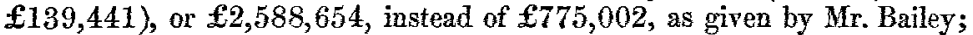
or the estimated liability is 39.7 per cent. on the sum assured, instead of $11 \cdot 9$.

Similar remarks apply to the Office (B), which had been 28 years in existence on 4th April, 1863, and which is represented as making a reserve equal to 9.4 per cent. of the sum assured. In this case, the sum assured is $\mathfrak{f 3}, 375,224$, and the available assets, after making provision for immediate liabilities, are $£ 964,275$, or 28.6 of the sum assured. I gather from the published acconnts of this Office, that the amount of the abatement allowed to members in the year $1863-4$ was $\mathfrak{f} 43,226$; and deducting this sum from the available assets, as above, it appears that the "reserve" of the Office is $£ 921,049$, or $27 \cdot 3$ on the sum assured, instead of 9.4 .

There can thus, I think, be no doubt that the reserves made by (A) and (B) for their liabilities, are not unduly small as compared with the reserves of other Offices; but whether the method employed to ascertain the abatement of premium for each year, is the most suitable, is a totally distinct question, mpon which it wonld not be proper to enter here.

That the method of treating the accounts adopted in the table is erroneons will perhaps be rendered more clear to some persons by the consideration of 
the case of an Office which should make an annual valtation and declare a reversionary bonus thereupon each year. Such an Office might declare, for a series of years, a reversionary bonus at the rate of $1 \frac{1}{2}$ per cent, per annum on the sum assured, and the expectation might be held ont to the assured that this rate of bonus would be maintained. In this case it would be manifestly improper to deduct from the assurance fund of the Society the value of the future reversionary bonus at the above rate, and style the balance the "estimated liability" of the Office. But this is precisely analogons to what has been done with the Offices (A) and (B).

I have already trespassed much on your space, but as I believe that a general interest is felt in our profession on these points, I will proceed to the consideration of another method by which the sufficiency and the magnitude of the reserve made by the offices in question may be testedviz., the valuation of individual policies. Take the case of a policy for $£ 100$ effected in the Office $(A)$ at the age 40 , at the annual premium $£ 3.17 \mathrm{~s}$, which has been in force $m$ years $(m<7)$; then the reserve made for this policy by the method of valuation pursued, is

$$
\begin{aligned}
& 100 \mathrm{~A}_{40+m}-3.85 \times\left(1+\frac{\left.\mathrm{B}_{\mathrm{m}}\right]_{40+m}}{a_{40}}-1.02 a_{40+m[\sqrt{6-m}}\right. \\
& =100 \mathrm{~A}_{40+m}-3 \cdot 85\left(1+a_{40+m}\right)+2 \cdot 83 a_{40+m \sqrt{6-m}} \\
& \text { i.e., } \mathrm{V}_{40 \mid m}=100 \mathrm{~A}_{40+m}-3 \cdot 85\left(1+a_{40+m}\right)+2 \cdot 83 \frac{\mathrm{N}_{46}}{\mathrm{D}_{40+m}} \text {. . . }
\end{aligned}
$$

For the preminm $\mathfrak{E} 385$ is payable in advance for $7-m$ years, and afterwards the premium is supposed to be reduced 73.5 per cent., or to become $£ 1 \cdot 02$.

Again, for a similar policy on the life of a member of the first series, which has been in force 7 years or more (say $7+n$ years), and upon which, therefore, there is a reduction of 83.5 per cent. on the premiums, the reduction being $£ 3 \cdot 21475$, and the reduced preminm $\mathfrak{E} 63524$, the value of the policy is

$$
\mathrm{V}_{4017+n}=100 \mathrm{~A}_{47+n}-63525\left(1+a_{47+n}\right) . . .
$$

\begin{tabular}{|c|c|c|c|c|c|}
\hline \multicolumn{3}{|c|}{$\begin{array}{c}\text { Polictes on tae Lives of Mearaers of } \\
\text { 2ND SERTES. }\end{array}$} & \multicolumn{3}{|c|}{ 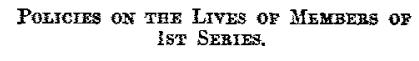 } \\
\hline & Formula (1). & $\begin{array}{l}\text { Carlise } \\
3 \text { per Cent. }\end{array}$ & & Formula (2). & $\begin{array}{l}\text { Carlisle } \\
3 \text { per Cent. }\end{array}$ \\
\hline $\begin{array}{l}V_{40: 1} \\
V_{40: 3} \\
V_{40: 3} \\
V_{40: 4} \\
V_{40: 5} \\
V_{4016}\end{array}$ & $\begin{array}{r}7 \cdot 790 \\
10 \cdot 882 \\
14 \cdot 089 \\
17 \cdot 451 \\
20 \cdot 983 \\
24 \cdot 713\end{array}$ & $\begin{array}{l}1 \cdot 394 \\
2 \cdot 773 \\
4 \cdot 155 \\
5 \cdot 585 \\
7 \cdot 056 \\
8 \cdot 589\end{array}$ & $\begin{array}{l}V_{40 ! 7} \\
V_{40 ! 5} \\
V_{40 \mid 9} \\
V_{40 ! 10} \\
V_{40 ! 33} \\
V_{40 \mid 12} \\
V_{40130} \\
V_{40 ! 30} \\
V_{40 \mid 40}\end{array}$ & $\begin{array}{l}27 \cdot 863 \\
28 \cdot 953 \\
30 \cdot 143 \\
31 \cdot 418 \\
32 \cdot 776 \\
34 \cdot 155 \\
52 \cdot 243 \\
65 \cdot 452 \\
76 \cdot 772\end{array}$ & $\begin{array}{l}10 \cdot 191 \\
11 \cdot 389 \\
13 \cdot 718 \\
15 \cdot 653 \\
17 \cdot 698 \\
19 \cdot 760 \\
36 \cdot 664 \\
55 \cdot 228 \\
70 \cdot 429\end{array}$ \\
\hline
\end{tabular}

By means of the formalæ (1) and (2), the values in columns (2) and (5) of the following table have been calenlated (at Carlisle 4 per cent.).

Table of Values of Policies. 
From a comparison of these values, two important conclusions may be drawn. Firstly, it should seem that the reserve made by the Office is greatly in excess, in the instances here given, of the values of the policies as given by the Carlisle 3 per cent. table; and it will be found, I believe, throughout the whole of life, that the reserve made by the valuation of the Office is in excess of that required by the Carlisle 3 per cent. valuation; from which it results that if a valuation of the Society were made by the Carlisle 3 per cent. table, there would be a much larger cash bonus divided than is now allowed in reduction of premium. Secondly, it will be noticed that the reserve made for recent policies is for several years greater than the amount of the premiums received, so that in fact every new policy issued causes loss on the subsequent valuations-reduces the divisible surplus-and makes the abatement of the preminm less than it would otherwise be.

This last observation opens ap a wide and tempting feld of investigation, but one which cannot be considered suitable for these pages. I therefore abstain from proceeding any further in that direction.

It will, of course, be understood that the values in the preceding table are not to be taken as the actual amounts reserved by the valuation of the Company. I believe that valuation is not conducted by the Carlisle table; and without being in possession of the table of mortality by which the valuations are conducted, it is impossible to assign the actual values of the policies. If the table in use is one which gives throughont a greater expectation of life than the Carlisle, then the values of the policies will be less than those given above; but it cannot be supposed that any table of mortality whatever would give such results as to vitiate the conclusions $I$ have ventured to draw from a comparison of the valnes in the above table.

In conclusion, I should wish to add, that in writing these remarks I have not been in any way actuated by a desire to recommend the system pursued by the two Offices $I$ have alluded to. I do not feel at liberty to express in these pages any opinion as to the merits of that system; and in all that I have said I have been carefnl to abstain from any expression of opinion, and to confine myself strictly to the discnssion of questions of fact.

$$
\text { I am, Sir, }
$$

Your obedient servant,

\author{
Equity and Law Life Assurance Soeiety, \\ 18, Lincoln's Inn Fields, \\ August, 1864. \\ T. B. SPRAGUE.
}

ON MR. HODGE'S REMARKS UPON THREE-LIFE SURYIVORSHIPS.

To the Ealitor of the Assuranee Magazine.

SrR, - I must beg the farour of a small space in your columns for a word or two in reference to Mr. Hodge's comments, at the last meeting of the Institute, upon Mr. Gray's account of my "Solutions of snrvivorship problems."

Mr. Hodge informed us that it was at one time his practice to calculate 